\title{
Intraoral Repair of All Ceramic Fixed Partial Denture Utilizing Preimpregnated Fiber Reinforced Composite
}

Süha Turkaslan ${ }^{a}$

Arzu Tezvergil-Mutluayb

\begin{abstract}
All ceramic fixed partial dentures (FPD)s exhibit enhanced biocompatibility and esthetics as compared to metal-ceramic restorations. However, framework fractures are frequently reported especially when the connector dimensions are inadequate to withstand the high tensile stresses. The repair of the failed connector would be desirable rather than the complete removal and renewal since the latter is an expensive and time consuming procedure. Furthermore, the replacement or removal of the restoration for extra-oral repair purposes might increase the risk of destroying the entire restoration or damaging the abutment teeth during the removal. This article presents a direct intra-oral method that may be used to repair the connector fractures of all-ceramic FPDs which are otherwise clinically satisfactory. In the present technique, the connector is reconstructed intraorally utilizing composite resin restorative material reinforced with E-glass-fiber. (Eur J Dent 2008;2:63-
\end{abstract} 68)

Key words: Fixed partial denture; All-ceramic; Fiber-reinforced composite; Intra-oral repair; Fracture.

\section{INTRODUCTION}

Despite the well-documented success rates with metal-ceramic restorations, the limitations in biocompatibility and optical qualities have

- a Department of Prosthodontics, Faculty of Dentistry, Suleyman Demirel University, Isparta, Turkey

b Department of Prosthetic Dentistry \& Biomaterials Science, Institute of Dentistry, University of Turku, Turku, Finland

- Corresponding author:

Assist. Prof. Dr. Süha TÜRKASLAN

Süleyman Demirel University

Faculty of Dentistry

Department of Prosthodontics

Isparta/TURKEY

Tel: +902462113263

Fax: +902462370607

E-mail: suhaturkaslanđyahoo.com

prompted the use of all-ceramic restorations. ${ }^{1}$ All-ceramic restorations, having no metal substructure, allow superior translucency and can be used in areas of high esthetic demand. ${ }^{2}$

However, the brittle nature of ceramic materials may lead to cracks or fractures. Since ceramic materials are very susceptible to failure under tensile loading, all-ceramic bridges require even more stringent mechanical properties than those needed for dental crowns. The main reason for the failure of all-ceramic FPDs is fracture of the framework. The fracture is usually located in the area between the retainer and pontic, originating from the gingival surface of the connectors where highest tensile stresses occurs, resulting in catastrophic fractures. ${ }^{1}$ 
When constructing FPDs, only a few ceramic materials are available: glass-infiltrated alumina (In-Ceram Alumina, In-Ceram Zirconia), heatpressed lithium disilicate-reinforced glass ceramic (IPS-Empress 2), and tetragonal stabilized zirconia. $^{3}$ In the 1990s three-unit FPDs made of glass infiltrated alumina ceramics were introduced for anterior use. ${ }^{4}$ The minimal recommended connector cross-section area is $12 \mathrm{~mm}^{2}{ }^{5}$ In 1998, three-unit FPDs made of lithium-disilicate glassceramic were introduced for the replacement of a missing tooth up to the first premolar, where the recommended connector cross-section area is 16 $\mathrm{mm}^{2} .3,6,7$

A fractured connector may result in the loss or dislodgement of a retainer, occlusal disharmony, food impaction besides esthetic problems. Such problems may often lead to the replacement of the entire restoration. Intraoral repair systems provide the possibility of repairing the FPD directly in the patients' mouth and prevent the replacement of the complete restoration. Mostly, particulate filler composites (PFC) are employed in intraoral repairs due to the esthetic properties and ease of application. However, the success is limited because PFC, as such, cannot resist the high tension forces. Fiber-reinforced composites (FRC)s have been used to increase the mechanical

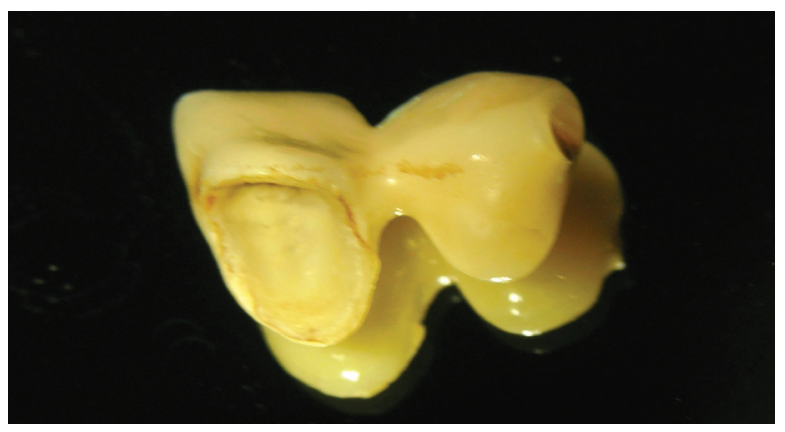

Figure 1. The mesial retainer crown and the pontic seperated from the distal crown because of connector fracture.

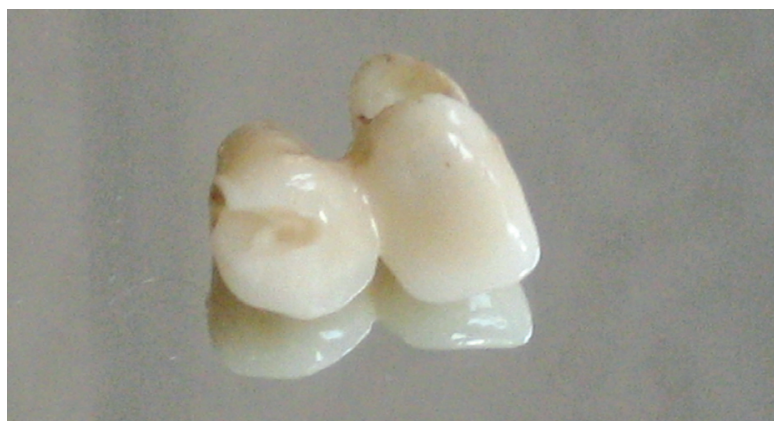

Figure 3. Groove formed on the palatal side of the pontic. properties of restorations without compromising the esthetic properties.8,9 They have been shown to have the ability to withstand tensile stresses and stop crack propagation at the adhesive interfaces. ${ }^{10-12}$

The paper reports intraoral repair of 3 unit heatpressed lithium disilicate all ceramic FPD which have been fractured at distal connector previously utilizing preimpregnated unidirectional E-glass fiber reinforced composite (FRC) (EverStick C\&B, StickTech, Finland).

\section{CASE REPORT}

32 years old male patient was referred to our clinic due to distal connector fracture of the three unit heat-pressed lithium disilicate-reinforced glass ceramic (IPS-Empress 2, Ivoclar, Vivadent, Schaan, Liechtenstein) FPD. Two all-ceramic FPDs were constructed 5 years ago because of missing lateral incisors but canines were in lateral incisors' position. The abutment teeth and the all ceramic FPD units both were in good condition except the fractured connector. Having observed that the pontic was disconnected from the distal crown and additionally luting cement was detached from the mesial abutment tooth 22 previously; the crown and the still attached pontic was removed from the mesial abutment tooth (Figure 1). The

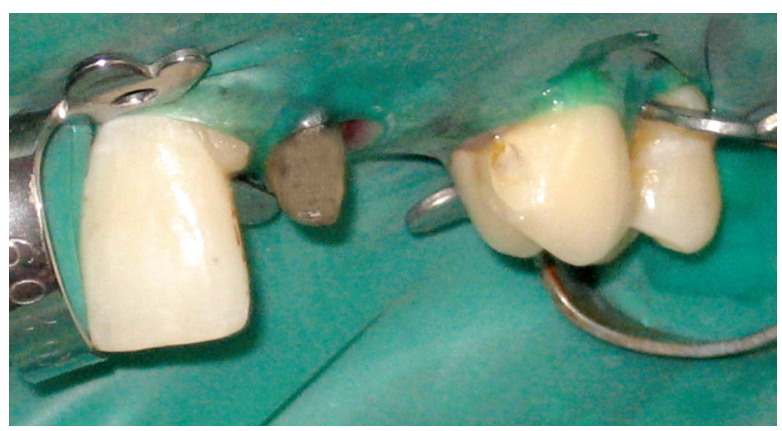

Figure 2. The isolated restoration area utilizing rubber-dam.

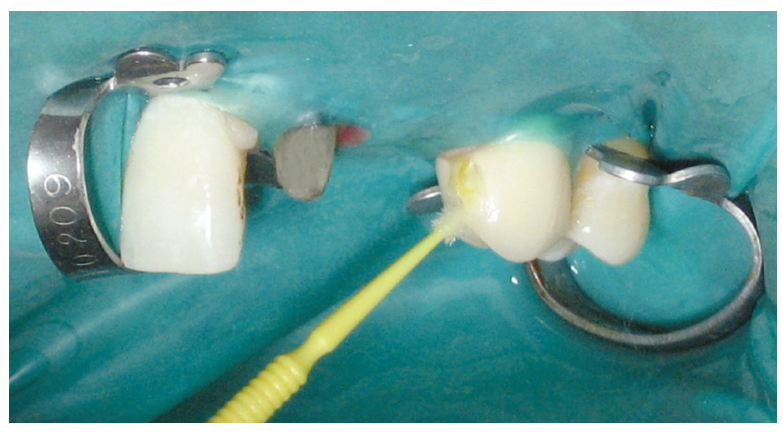

Figure 4. The grooves were acid etched with $9 \%$ hydrofluoric acid and silane coupling agent was applied. 
area was isolated by use of a rubber-dam and grooves prepared both on the occlusal part of distal crown intraorally and on the palatal side of pontic extraorally (Figures 2 and 3). The grooves were treated with air-particle abrasion using 50 $\mu \mathrm{m} \mathrm{Al} \mathrm{O}_{2} \mathrm{O}$ (Korox, Bego, Germany) with a chair side air-abrasion device (CoJet, 3M-ESPE, Germany) from a distance of $10 \mathrm{~mm}$ at a pressure of 250 kPa bar for $10 \mathrm{~s}$. Air-particle abraded surfaces were treated by $9 \%$ hydrofluoric acid (Pulpdent Corporation, USA) for $5 \mathrm{~min}$ and finally a silane coupling agent (Pulpdent Corporation, USA) was applied (Figure 4) and air-dried.

Before application, preimpregnated unidirectional E-glass FRC (EverStick C\&B, StickTech, Finland) was cut $0.5 \mathrm{~mm}$ short of the finish line of the prepared grooves (Figure 5) and further-impregnated with light-curing adhesive resin (Stick Resin, Stick Tech, Finland) for 10 min in a dark container. The detached crown was cemented onto the mesial abutment tooth utilizing dual-cure composite resin luting cement (Panavia F2.0, Kuraray, Japan) following the manufacturer's recommendations (Figure 6). Light curing adhesive (One-Step Plus, Bisco, Schaumburg, USA) was applied on the surface of neighbor grooves and light irradiated for $20 \mathrm{~s}$. Flowable composite (EcoFlow, Ivoclar-Vivadent, Schaan, Liechtenstein)

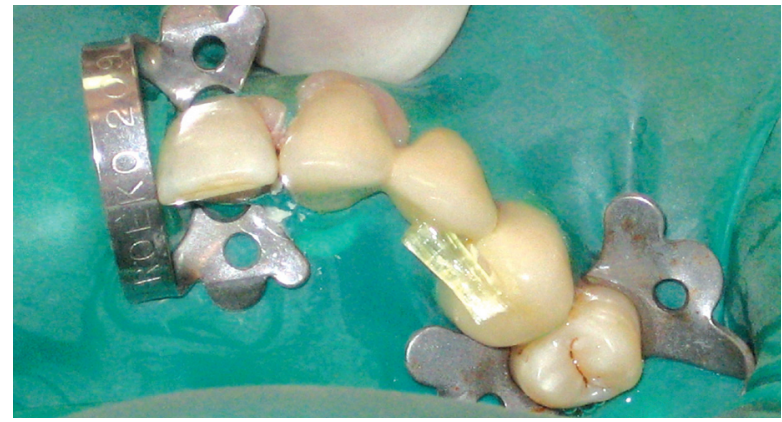

Figure 5. FRC was cut 0,5 mm short of finish line of grooves.

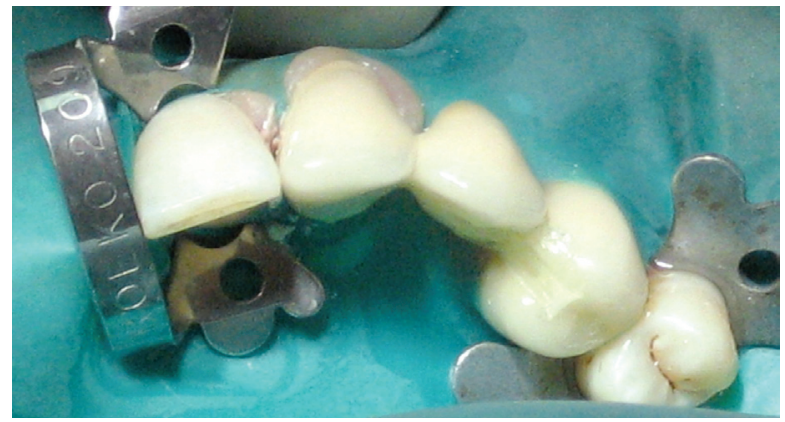

Figure 7. FRC adapted in the grooves utilizing transparent silicone block. was applied prior to the application of the preimpregnated FRC and the FRC was adapted in the grooves using a transparent silicone block. Supporting the pontic from the facial side the FRC and flowable composite light irradiated for $40 \mathrm{sec}$ beyond the silicone block (Figure 7). The restored area was covered with flowable composite filling the entire groove and covering the connector area, and light cured (Figure 8). Excess composite was removed with abrasive discs and the restored area was checked to avoid any occlusal interference (Figure 9). Also the pontic checked on lateral excursions to diminish inadequate forces which may lead to re-fracture of restored area. The patient was recalled in 3 weeks (Figure 10) and no complication was observed during 6 months clinic service.

\section{DISCUSSION}

In the case of short 3-unit bridges, the fracture probability of theveneerundersubcriticalconditions is markedly low for connector diameters equal or larger than $\sim 4 \mathrm{~mm}$. By designing connectors with diameter larger than this minimum value, the risk of failure due to subcritical crack growth is expected to be lower than $5 \%$. On the other hand, when the recommended connector dimensions are not possible due to the limited crown height,

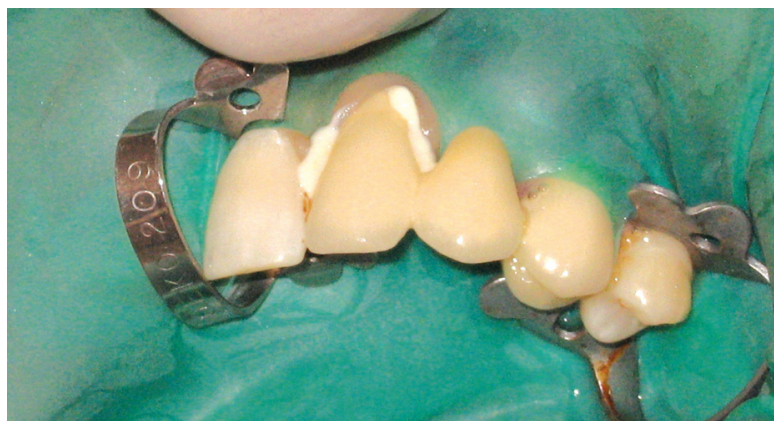

Figure 6. The mesial retainer crown cemented on the mesial abutment tooth.

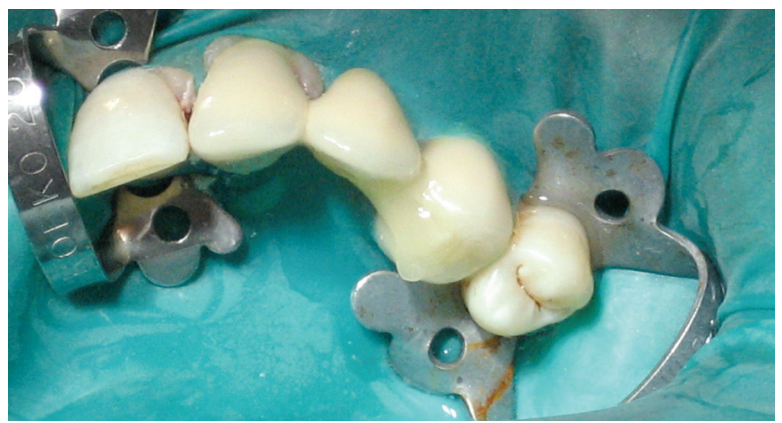

Figure 8. The restored area was covered with flowable composite. 
failures due to the crack propagation from the veneer surface is expected to occur even for shorter 3-unit bridges for the IPS-Empress 2.,13 In the presented case report, the reason for the initial failure was probably due to the fact that, the connector was not satisfying the recommended minimum thickness criteria for the standards of heat-pressed lithium disilicate-reinforced glass ceramics as the gingivo-occlusal space was limited.

Connector fracture is the primary reason of failure when all-ceramic FPDs' failure modes are evaluated. ${ }^{14}$ Miscellaneous repair techniques have been used as alternatives to the expensive and time-consuming procedure of re-constructing the prostheses. Repair methods may be classified into 2 types, the direct method and the indirect method. ${ }^{15,16}$ Direct repairs include techniques that use composites applied directly to the fractured restoration, ${ }^{17,18}$ and indirect repairs include those that use porcelain that is applied as a laboratory procedure and is bonded to the fractured restoration. ${ }^{19-20}$ Various methods of repairing fractured porcelain with composite have been reported. 17,18,21,22 Direct intraoral repair of fractured porcelain traditionally relied on mechanical roughening of the fractured surface, followed by application of a silane coupling agent to enhance the resin-to-porcelain bond. In the present study, the ceramic grooves' surfaces was firstly air abraded and acid etched as it is reported, lithium disilicate ceramic specimens treated with airborne-particle abrasion and acidetching technique displays the highest tensile bond strength values to the composite resin evaluated in the study. ${ }^{23}$

The primary advantages of using composites for repair are less chair time, lower cost, and

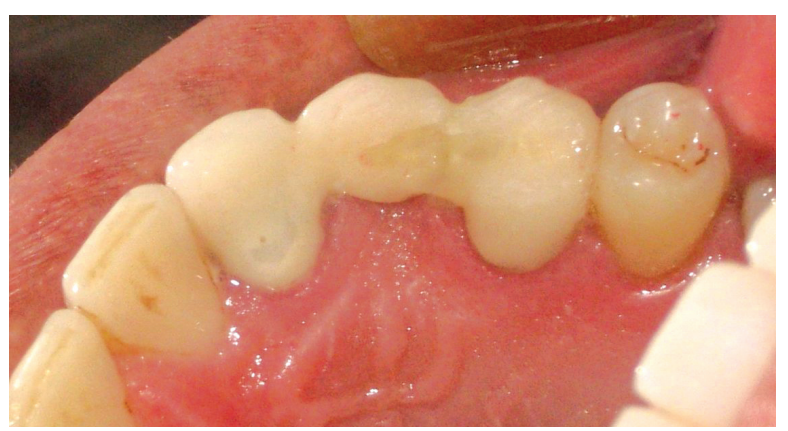

Figure 9. Occlusal view of the restored area after finishing and polishing procedures. ease of application. However, the advantages are limited due to the low strength, poor wear qualities which is known to be overcome by use of FRC. The reinforcing effect of FRC depends on the cohesive strength of the polymer matrix as well as fiber type, volume fraction, orientation and the quality of the fiber-polymer matrix interface. ${ }^{24}$ The preimpregnation of fibers with the light polymerizable resin system by the manufacturer was shown to be of great importance to optimize the properties. ${ }^{25}$

The continuous unidirectional FRC can provide the highest strength and stiffness in the direction of fibers. ${ }^{25}$ Tension side reinforcement was shown to be effective in increasing the flexural strength and static load-bearing capacity of the restorations. ${ }^{26}$

The effect of span-to-thickness ratio on flexural properties of FRC used for dental restorations was studied by Karmaker and Prasad for both the conditions of constant thickness and constant support span. Based on their experimental investigation, the absolute load bearing capabilities were higher than expected. Their findings suggest that the presence of fibers within the bridge could be capable of supporting considerably higher loading than the composite material properties allow. ${ }^{27,28}$

In this case, FRC was used to improve the mechanical properties of the composite material. Nevertheless, increasing the amount of FRC by using two or more fiber bundles may result in a stiffer connector but trying to create enough space for more fiber material may result in weakening the ceramic itself. The fiber used in the repair process is $1,5 \mathrm{~mm}$ in diameter but the highest flexural strength reported considering Empress 2 material is $407 \pm 45 \mathrm{MPa}^{29}$ where $1144 \pm 99.9 \mathrm{MPa}$ is reported ${ }^{30}$ for the glass fiber used in this case

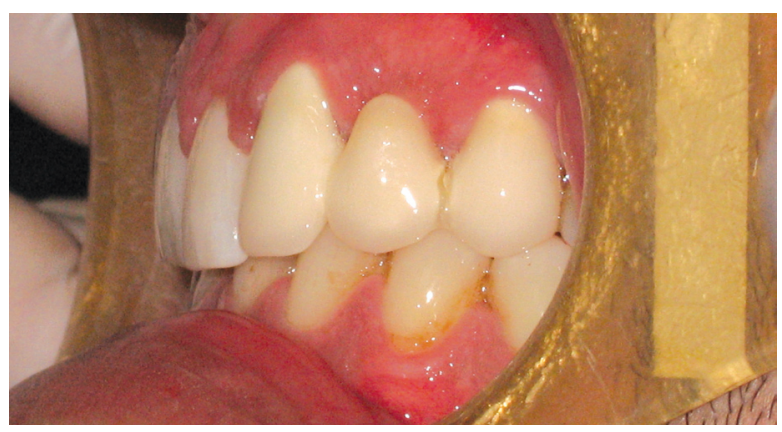

Figure 10. Facial view of the restored area after 3 weeks. 
report. Moreover FRCs ability to change and slow crack propagation result in stiffer restorations with higher fracture resistances. 11,12,31,32 Therefore no enlargement is intended as the flexural strength values advised the enough stiffness of the new connector leaving the gingival proximal area free for routine hygiene procedures.

\section{CONCLUSIONS}

The connector repair of a heat-pressed lithium disilicate-reinforced glass ceramic (IPS-Empress 2) FPD with FRC in combination with flowable composite provided sufficient fracture strength. Therefore the replacement of the complete restoration may be avoided.

The intraoral repair technique, may be considered as less expensive and a less timeconsuming procedure. The primary disadvantage of the technique selected is low mechanical properties which may be improved utilizing FRC.

The esthetic appearance of the FPD is still acceptable for the patient since shade matching materials were used during the repair procedure and with the FRC the connector area was acceptable according to the esthetic criterions of the patient.

\section{REFERENCES}

1. Sadowsky SJ. An overview of treatment considerations for esthetic restorations: A review of the literature. $J$ Prosthet Dent 2006;96:433-442.

2. Studart AR, Filser F, Kocher P, Lüthy H, Gauckler LJ. Cyclic fatigue in water of veneer-framework composites for allceramic dental bridges. Dent Mater 2007;23:177-183.

3. Lüthy H, Filser F, Loeffel O, Schumacher M, Gauckler LJ, Hammerle CHF Strength and reliability of four-unit allceramic posterior bridges. Dent Mater 2005;21:930-937.

4. Sorensen JA, Knode H, Torres TJ. In-ceram all-ceramic bridge technology. Quintessence Dent Technol 1992;15:4146.

5. McLaren EA. All-ceramic alternatives to conventional metal-ceramic restorations. Compend Contin Educ Dent 1998; 19:307-308.

6. Sorensen JA, Cruz M, Mito WT, Raffeiner 0, Meredith HR, Foser HP. A clinical investigation on three-unit fixed partial dentures fabricated with a lithium disilicate glass-ceramic. Pract Peridont Aesthet Dent 1999;11:95-106.

7. Raigrodski AJ, Chiche GJ. The safety and efficacy of anterior ceramic fixed partial dentures: a review of the literature. $J$ Prosthet Dent 2001;86:520-525.
8. Goldberg AJ, Freilich MA. An innovative pre-impregnated glass fiber for reinforcing composites. Dent Clin North Am 1999:43:127-133.

9. Vallittu PK. The effect of glass fiber reinforcement on the fracture resistance of a provisional fixed partial denture. $J$ Prosthet Dent 1998;79:125-130.

10. Vallittu PK. Use of woven glass fibres to reinforce a composite veneer. A fracture resistance and acoustic emission study. J Oral Rehabil 2002;29:423-429.

11. Tezvergil A, Lassila LVJ, Yli-Urpo A, Vallittu PK. Repair bond strength of restorative resin composite to fiber-reinforced composite substrate. Acta Odontol Scand 2004;62:51-60.

12. Ozcan M, van der Sleen JM, Kurunmaki H, Vallittu PK. Comparison of repair methods for ceramic-fused-to-metal crowns. J Prosthodont 2006;15:283-288.

13. Tinschert J, Natt G, Mautsch W, Augthun M, Spikermann H. Fracture resistance of lithium disilicate-, alumina-, and zirconia-based three-unit fixed partial dentures: a laboratory study. Int J Prosthodont 2001;14:231-238.

14. Kelly JR, Tesk JA, Sorensen JA. Failure of all-ceramic fixed partial dentures in vitro and in vivo: analysis and modeling. $J$ Dent Res 1995;74:1253-1258.

15. Appleby DC. Repair of fractured connectors in a provisional fixed partial denture. J Prosthet Dent 2001;84:449-450.

16. Galiatsatos AA. An indirect repair technique for fractured metal-ceramic restorations: a clinical report. J Prosthet Dent 2005;93:321-323

17. Bertolotti RL, Lacy AM, Watanabe LG. Adhesive monomers for porcelain repair. Int J Prosthodont 1989;2:483-489.

18. Kupiec KA, Wuertz KM, Barkmeier WW, Wilwerding TM. Evaluation of porcelain surface treatments and agents for composite-to-porcelain repair. J Prosthet Dent 1996;76:119124.

19. Barreto MT, Bottaro BF. A practical approach to porcelain repair. J Prosthet Dent 1982;48:349-351.

20. Chung K, Hwang Y. Bonding strengths of porcelain repair system with various surface treatments. J Prosthet Dent 1997;78:267-274.

21. Appeldoorn RE, Wilwerding TM, Barkmeier WW. Bond strength of composite resin to porcelain with newer generation porcelain repair systems. J Prosthet Dent 1993;70:6-11.

22. Cardoso AC, Spinelli Filho P. Clinical and laboratory techniques for repair of fractured porcelain in fixed prostheses: a case report. Quintessence Int 1994;25:835838.

23. Kim BK, Bae HEK, Shim JS, Lee KW. The influence of ceramic surface treatments on the tensile bond strength of composite resin to all-ceramic coping materials. J Prosthet Dent 2005;94:357-362. 
24. Ellakwa AE, Shortall AC, Marquis PM. Influence of fiber type and wetting agent on the flexural properties of an indirect fiber reinforced composite. J Prosthet Dent 2002;88:485490.

25. Vallittu PK. Flexural properties of acrylic resin polymers reinforced with unidirectional and woven glass fibers. $J$ Prosthet Dent 1999;81:318-326.

26. Dyer SR, Lassila LV, Jokinen M, Vallittu PK. Effect of fiber position and orientation on fracture load of fiber-reinforced composite. Dent Mater 2004;20:947-955.

27. Karmaker A, Prasad A. Effect of design parameters on the flexural properties of fibre-reinforced composites. J Mater Sci Lett 2000;19:663-665.

28. Li W, Swain MV, Li Q, Ironside J, Steven GP. Fiber reinforced dental bridge. Part I: experimental investigation. Biomaterials 2004;25:4987-4993.

29. Albakry M, Guazzato M, Swain MV. Biaxial flexural strength, elastic moduli and $\mathrm{x}$-ray fiffraction characterization of three pressable all-ceramic materials. $J$ Prosthet Dent 2003;89:374-380.

30. Lassila LVJ, Tanner J, Le Bell AM, Narva K, Vallittu PK. Flexural properties of fiber reinforced root canal posts. Dent Mater 2004;20:29-36.

31. Fennis WM, Tezvergil A, Kuijs RH, Lassila LV, Kreulen CM, Creugers NH, Vallittu PK. In vitro fracture resistance of fiber reinforced cusp-replacing composite restorations. Dent Mater 2005;21:565-572.

32. TezvergilA, Lassila LVJ, Vallittu PK. The shear bond strength of bidirectional and random-oriented fiber-reinforced composite to tooth structure. J Dent 2005;33:509-516. 